ARTICLE

Received 8 May 2012 | Accepted 28 Jan 2013 | Published 5 Mar 2013

DOI: $10.1038 /$ ncomms2561

\title{
Actin-based confinement of calcium responses during Shigella invasion
}

\author{
Guy Tran Van Nhieu1,2,3,4, Bing Kai Liu1,2,3,4,5,6, Jie Zhang1,2,3,4,5,6, Fabienne Pierre 1,2,3,4,5,6, Sylvie Prigent ${ }^{5,6}$, \\ Philippe Sansonetti ${ }^{7,8}$, Christophe Erneux ${ }^{9}$, Jung Kuk Kim ${ }^{10,11}$, Pann-Ghill Suh ${ }^{10,11}$, Geneviève Dupont ${ }^{12}$ \\ \& Laurent Combettes 5,6
}

Shigella, the agent of bacillary dysentery, invades epithelial cells by locally inducing actin reorganization. Upon cell invasion, Shigella induces calcium $\left(\mathrm{Ca}^{2+}\right)$ signalling, but its role in invasion has remained unclear. Here we show that components involved in inositol 1, 4, 5- trisphosphate $\left(\mathrm{InsP}_{3}\right)$ signalling are implicated in Shigella invasion. Although global $\mathrm{Ca}^{2}+$ responses are dispensable for bacterial invasion, local $\mathrm{Ca}^{2}+$ responses of unprecedented long duration are associated with invasion sites. Fluorescence recovery after photobleaching experiments indicate that diffusion of small solutes is hindered at Shigella-invasion sites and that diffusion hindrance is dependent on bacterially induced actin reorganization. Computational simulations and experimental challenge of the model support the notion that local accumulation of $\operatorname{InsP}_{3}$ permitted by restricted diffusion and enrichment of $\operatorname{lnsP}_{3}$ receptors account for sustained local $\mathrm{Ca}^{2+}$ increases at entry sites. Thus, cytoskeletal reorganization through diffusion hindrance shapes the duration of local $\mathrm{Ca}^{2}+$ signals.

\footnotetext{
${ }^{1}$ Equipe Communication Intercellulaire et Infections Microbiennes. Centre de Recherche Interdisciplinaire en Biologie (CIRB). Collège de France. 11 Place Marcelin Berthelot, Paris 75005, France. ${ }^{2}$ Institut National de la Santé et de la Recherche Médicale (Inserm) U1050, Paris 75005, France. ${ }^{3}$ Centre National de la Recherche Scientifique (CNRS) UMR7241, Paris 75005, France. ${ }^{4}$ MEMOLIFE Laboratory of excellence and Paris Sciences et Lettres, Paris 75005, France. ${ }^{5}$ Université Paris Sud, UMRS757, Orsay F-91405, France. ${ }^{6}$ Inserm, UMRS757, Orsay F-91405, France. ${ }^{7}$ Unité de Pathogénie Microbienne Moléculaire. Département de Biologie Cellulaire et Infections. Institut Pasteur, Paris 75015, France. ${ }^{8}$ Inserm U786, Paris 75015, France. ${ }^{9}$ Interdisciplinary Research Institute (IRIBHM), Université Libre de Bruxelles, Campus Erasme, Bldg C, 808 Route de Lennik, Brussels 1070, Belgium. ${ }^{10}$ Division of Molecular and Life Science, Pohang University of Science and Technology, Pohang 790-784, Republic of Korea. ${ }^{11}$ School of Nano-Biotechnology and Chemical Engineering, Ulsan National Institute of Science and Technology, Ulsan 689-798, Republic of Korea. ${ }^{12}$ Unité de Chronobiologie Théorique. Université Libre de Bruxelles. CP231, Boulevard du Triomphe, 1050 Brussels, Belgium. Correspondence and requests for materials should be addressed to G.T.V.N. (email: guy.tran-van-nhieu@college-de-France.fr).
} 
pon ingestion, Shigella invades the colonic mucosa where it elicits an intense inflammatory reaction leading to tissue destruction $^{1-3}$. The virulence of Shigella depends on a type III secretion system (T3SS), which injects bacterial effectors into target cells ${ }^{4}$. The T3SS is inactive under basal conditions, but upon cell contact, secretes two hydrophobic substrates, IpaB and IpaC, which insert into host cell membranes, forming a 'tranlocator' required for the injection of T3SS effectors. Cytoskeletal reorganization by these effectors lead to bacterial invasion, a process that implicates a coordination of RhoGTPases and tyrosine kinase signalling at the membrane $e^{3,5}$. In addition to its role in T3SS effector translocation, IpaC also induces actin polymerization responsible for the formation of cell extensions that surround the bacterium ${ }^{6}$. Actin polymerization at entry sites is favoured by IpgB1, a Shigella T3S-injected effector, that recruits ELMO/Dock180 and amplifies membrane rufflings at bacterial entry sites ${ }^{7}$. IpaA binds to the focal adhesion protein vinculin and triggers bacterial anchorage in bacterially induced actin foci, as well as the depolymerization of actin required for efficient invasion $^{3,8,9}$. Shigella invasion also triggers global $\mathrm{Ca}^{2+}$ responses implicated in the opening of connexin hemichannels and cell-cell signalling dependent on ATP release ${ }^{10}$. Hemichannel-mediated signalling favours bacterial invasion and dissemination across the epithelial layer, and participate in the induction of water release by colonocytes during in vivo infection of mice with Citrobacter rodentium ${ }^{10,11}$.

Many bacterial pathogens perturb global cell $\mathrm{Ca}^{2}+$ homoeostasis, either through secreted bacterial toxins or during direct interactions with host cells ${ }^{12-15}$. Insertion of the T3SS translocator into host cell membranes may trigger intracellular $\mathrm{Ca}^{2+}$ increases linked to its pore-forming activity and $\mathrm{Ca}^{2+}$ influx, or by inducing alterations of the host plasma membranes leading to $\mathrm{Ins}_{3}$-dependent signalling, resulting from the mobilization of $\mathrm{Ca}^{2+}$ from intracellular stores ${ }^{16,19}$. $\mathrm{InsP}_{3}$ may in turn induce oscillatory patterns of global intracellular $\mathrm{Ca}^{2+}$ in individual cells ${ }^{10,18,19}$. Although global $\mathrm{Ca}^{2+}$ responses may have long-term consequences by activating gene transcription, local $\mathrm{Ca}^{2+}$ signals, evoked by weak InsP $\mathrm{P}_{3}$ stimuli, can occur independently of global $\mathrm{Ca}^{2+}$ increases. These $\mathrm{Ca}^{2+}$ signals, confined in a small cytoplasmic region around the $\mathrm{Ca}^{2+}$ releasing sites ${ }^{20}$, correspond to elementary events of $\mathrm{Ca}^{2}+$ release from discrete clusters of channels from intracellular pools ${ }^{21}$. Local $\mathrm{Ca}^{2+}$ signals occuring within the vicinity of the plasma membrane could directly regulate $\mathrm{Ca}^{2+}$-dependent processes, including processes involving cortical actin reorganization. ${ }^{22-24}$.

Here we show that InsP $_{3}$-mediated signalling is required for Shigella invasion of epithelial cells. Shigella triggers the recruitment of $\mathrm{InsP}_{3}$ receptors, PLC- $\beta 1$ and PLC- $\delta 1$ at entry sites, shown to participate in the invasion process. Unusually longlasting local $\mathrm{Ca}^{2}+$ responses are correlated with restriction of diffusion linked to actin polymerization at bacterial invasion sites and the local activation of mitochondria at entry sites.

\section{Results}

Role of Ins $\mathrm{P}_{3}$-mediated signalling during Shigella invasion. We used an InsP $_{3}-5$ phosphatase $\left(\right.$ InsP $\left._{3}-5 \mathrm{P}\right)$ expressed from a green fluorescent protein (GFP) polycistronic construct to investigate the implication of $\mathrm{InsP}_{3}$-mediated $\mathrm{Ca}^{2+}$ signalling in Shigella invasion $^{25}$. As expected, $\mathrm{InsP}_{3}-5 \mathrm{P}$-transfected cells did not elicit whole-cell $\mathrm{Ca}^{2+}$ responses in response to relevant agonists or to Shigella challenge, indicating efficient inhibition of $\mathrm{InsP}_{3^{-}}$ mediated signalling (Fig. 1a and Supplementary Fig. S1). For the pIRES-5P-GFP transfection, bacterially induced actin foci were scored in transfected cells identified using GFP fluorescence. Ins $_{3}-5 \mathrm{P}$ transfection, strikingly, led to inhibition of bacterially induced actin foci, with only $20 \%$ of foci forming per cell compared with GFP-transfected cells (Fig. 1b,d and Supplementary Fig. S2). Consistent with the implication of $\mathrm{InsP}_{3}$ mediated signalling in Shigella invasion, immunofluorescence labelling indicated that $\operatorname{Ins}_{3}-\mathrm{R}$ type $1\left(\mathrm{InsP}_{3} \mathrm{R} 1\right)$ and type 3 $\left(\right.$ Ins $\left.P_{3} \mathrm{R} 3\right)$, the main Ins $_{3} \mathrm{Rs}$ expressed in $\mathrm{HeLa}$ cells ${ }^{26}$, were recruited at bacterially induced actin foci, although recruitment appeared less consistent for $\mathrm{Ins}_{3} \mathrm{R} 3$ (Supplementary Fig. S3). In contrast, an ER-YFP probe and anti-calnexin staining did not show particular enrichment at Shigella-invasion sites (Supplementary Fig. S3). To confirm the implication of InsP $3_{3}$ mediated signalling in Shigella invasion, we used siRNAs directed against Ins $\mathrm{P}_{3}$ Rs. As previously described, inhibition of Ins $\mathrm{P}_{3} \mathrm{Rs}$ expression impaired $\mathrm{Ca}^{2}+$ responses upon agonist stimulation ${ }^{26}$ (Supplementary Fig. S4). Consistent with results obtained with the Ins $\mathrm{P}_{3}-5 \mathrm{P}$, bacterially induced actin foci formation was depressed in cells treated with anti-Ins $\mathrm{P}_{3} \mathrm{Rs}$ siRNAs, with a $68 \%$ inhibition compared with control cells (Fig. 1c,d).

Shigella invasion does not require global $\mathrm{Ca}^{2}+$ responses. To deplete cells from $\mathrm{Ca}^{2}+$, while limiting cytotoxic effects associated with the use of $\mathrm{Ca}^{2+}$ chelators over the length of the expriments, cells were incubated in $\mathrm{Ca}^{2+}$-free medium and treated with 2, 5-di (tert-butyl)-1, 4-benzohydroquinone (tBuBHQ), an inhibitor of the sarco-endoplasmic $\mathrm{Ca}^{2}+$ ATPase involved in the replenishing of intracellular pools, at a final concentration of $25 \mu \mathrm{M}$ at $37^{\circ} \mathrm{C}$ for $10 \mathrm{~min}$ (Fig. 1e). Under such treatment, cells did not show significant alterations of their morphology but failed to show global $\mathrm{Ca}^{2}+$ responses when stimulated with $30 \mu \mathrm{M}$ histamine or when challenged with Shigella (Fig. 1e). In contrast, following $\mathrm{Ca}^{2+}$ depletion and tBuBHQ treatment, long-lasting local $\mathrm{Ca}^{2+}$ responses could still be observed upon Shigella infection (Supplementary Fig. S5). Although tBuBHQ treatment in $\mathrm{Ca}^{2+}$-free medium inhibited global $\mathrm{Ca}^{2}+$ responses induced by Shigella, bacterially induced actin foci occurred at levels indistinguishable from untreated controls (Fig. 1c-e). Remarkably, when cells were treated with the $\mathrm{Ca}^{2+}$ chelator BAPTA-AM, known to inhibit global as well as local $\mathrm{Ca}^{2}+$ responses ${ }^{20,21}$, the average frequency of actin foci per cell decreased significantly, with only $3 \pm 1.6 \%$ observed when compared with control untreated cells (Supplementary Fig. S6). Together, these results implicate $\mathrm{InsP}_{3}$-mediated signalling, but not global $\mathrm{Ca}^{2}+$ responses, in Shigella-induced cytoskeletal reorganization and bacterial invasion, suggesting that local $\mathrm{Ca}^{2+}$ signals that depend on $\mathrm{InsP}_{3}$ synthesis participate in Shigella invasion.

Local $\mathrm{Ca}^{2}+$ responses associated with Shigella actin foci. Transient and local $\mathrm{Ca}^{2+}$ signals, remaining confined to a small cytoplasmic region at $\mathrm{Ca}^{2}{ }^{+}$-releasing sites, have been described to occur independently of global $\mathrm{Ca}^{2+}$ responses, in association with cytoskeletal reorganization ${ }^{23,24}$. The implication of $\mathrm{InsP}_{3}$ signalling in Shigella invasion prompted us to study local $\mathrm{Ca}^{2+}$ responses during bacterial entry.To study local $\mathrm{Ca}^{2}+$ responses during bacterial entry, Fluo-4-loaded cells were challenged with Shigella and subjected to high-speed fluorescence microscopy (HSFM). A major difficulty in these experiments is that, as opposed to $\mathrm{Ca}^{2+}$ agonists, bacterial invasion does not occur in a fully synchronized manner and need to be analysed over several minutes. Because in our conditions, HSFM over prolonged acquisition was not compatible with bacterial invasion, we performed series of 'snap-shot' HFSM analysis at various time points following bacterial challenge. As shown in Fig. 2, local $\mathrm{Ca}^{2}+$ responses induced by bacterial challenge could be detected as early as $5 \mathrm{~min}$ following bacterial challenge, with an average 
a

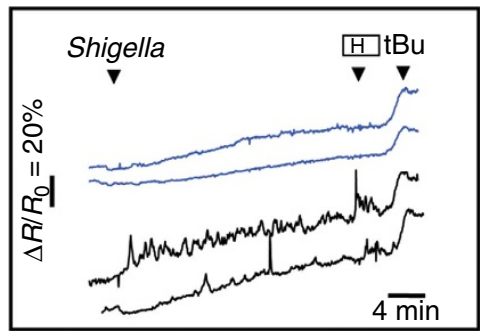

d

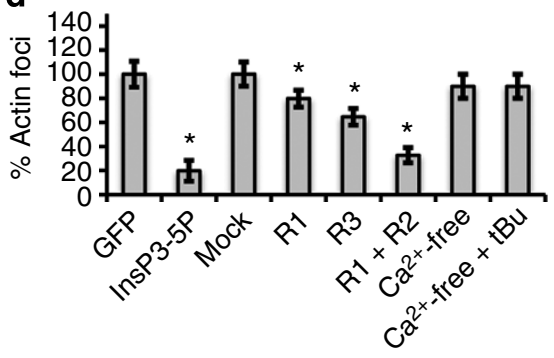

e

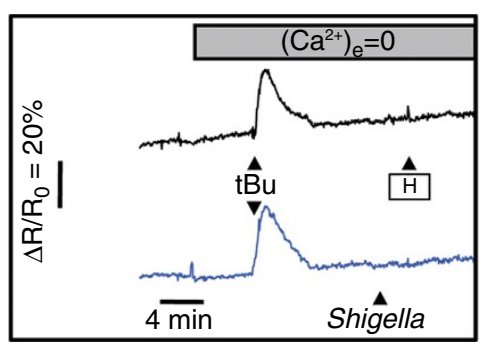

b

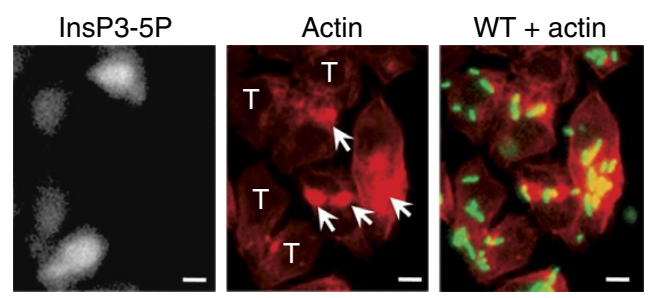

C
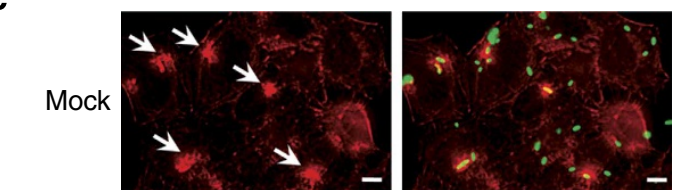

R1
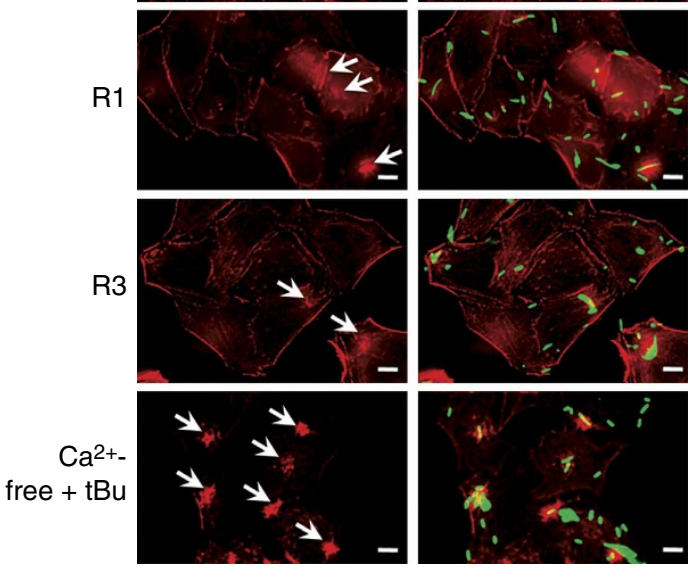

Figure1 | Ins $\mathrm{P}_{\mathbf{3}}$-mediated signalling is required for Shigella-induced actin foci formation. Variations of global intracellular $\mathrm{Ca}^{2+}$ in $\mathrm{HeLa}$ cells transfected with the InsP $\mathrm{P}_{3}-5 \mathrm{P}$ (blue), or GFP (black), challenged with wild-type (WT) Shigella in EM buffer (a), or in $\mathrm{Ca}^{2+}$-free medium (e). $\mathrm{H}$, addition of histamine at a $30 \mu \mathrm{M}$ final concentration. Cells tested did not show any $\mathrm{Ca}^{2+}$ response when stimulated with histamine $100 \mu \mathrm{M}$ final concentration or following Shigella infection. (b,c) Cells challenged with invasive Shigella labelled by anti-lipopolysaccharide staining (green) and F-actin (red). Arrows: actin foci. (b) T, cells transfected with InsP $\mathrm{P}_{3}-5 \mathrm{P}$. (c) Cells mock-transfected, transfected with siRNAs against InsP $\mathrm{P}_{3} \mathrm{R} 1(\mathrm{R} 1)$ or $\operatorname{Ins}_{3} \mathrm{R} 3(\mathrm{R} 3)$, or incubated in $\mathrm{Ca}^{2+}{ }_{-}$-free buffer and stimulated with tBuBHQ $\left(\mathrm{Ca}^{2+}\right.$-free $\left.+\mathrm{tBu}\right)$. Scale bar, $5 \mu \mathrm{m}$. (d) Actin foci were scored in cells labelled as in $\mathbf{b}, \mathbf{c}$, and average values $\pm \mathrm{s}$.e.m.

were expressed as a percentage of the values obtained for: GFP (129 cells, $N=3$ ) for InsP ${ }_{3}$-5P-transfected cells (129 cells, $N=3$ ); Mock-transfected cells $\left(1,270\right.$ foci, 2,558 cells, $N=4$ ) for cells transfected with siRNAs against InsP ${ }_{3} R 1$ ( 787 foci, 1,966 cells, $\left.N=4\right)$, InsP $P_{3} R 3(730$ foci, 2,298 cells, $N=4)$, or InsP $\mathrm{P}_{3} \mathrm{R} 1$ and $\mathrm{InsP}_{3} \mathrm{R} 3$ (269 foci, 1,623 cells, $N=4$ ); cells challenged in EM buffer for cells in $\mathrm{Ca}^{2+}$-free buffer or subjected to Ca ${ }^{2+}-$ depletion treatment ( $>200$ cells, $N=3$ ). ${ }^{*}$, statistical significance relative to control was tested using an unpaired Student's $t$-test with unequal variance. $P=10^{-7}$ (InsP3-5P); $P=0.0142(\mathrm{R} 1) ; P=0.001(\mathrm{R} 3) ; P=2 \times 10^{-5}(\mathrm{R} 1+\mathrm{R} 3)$.

duration of $100-400 \mathrm{~ms}$ with an increase in $\mathrm{Ca}^{2}+$ concentration corresponding on average to $6.9 \%$ of the maximal cytosolic concentration achieved during global responses, similar to the previously described 'puffs'21,24 (Fig. 2a). These 'puff-like' responses were induced in $30-50 \%$ of the cells challenged and observed with wild type as well as the T3SS-deficient mxiD strains, indicating that these occurred independent of invasion and were likely to be induced by bacterial adhesion onto the cell surface (Fig. 2a,b). Strikingly, however, atypical sustained local responses associated with an area larger than $10 \mu \mathrm{m}^{2}$ were specifically observed for cells challenged with invasive Shigella, but never with the non-invasive mxiD mutant strain. For the analysis, these sustained local $\mathrm{Ca}^{2}+$ responses were arbitrarily categorized into responses lasting from 0.4 to $5 \mathrm{~s}$, with increases in $\mathrm{Ca}^{2}+$ concentration ranging from 11 to $47 \%$ of the maximal response, referred to as 'INTs' for 'responses of intermediate duration' (Fig. 2c,d), or $\mathrm{Ca}^{2+}$ responses lasting between 5 and $20 \mathrm{~s}$, called 'RATPs' for 'Responses Associated with Trespassing Pathogens', which on average corresponded to $55 \%$ of the maximal response (Fig. 2e,f). INTs and RATPs were seldom detected at $5 \mathrm{~min}$ following cell challenge by wild-type Shigella, but occurred with an increased frequency upon further incubation to reach $40 \%$ of cells after $15 \mathrm{~min}$ (Fig. 2c,d). Ratiometric measurements performed in cells loaded with a combination of Fluo- 4 and Fura-red ruled out the possibility of a bias linked to accumulation of the probe in RATPs (Supplementary Fig. S7). Because of their size and timing of occurence, we suspected that INTs and RATPs were associated with bacterial invasion sites. To test this, samples were visualized by phase contrast microscopy following HSFM. In all samples analysed, INTs and RATPs were always associated with bacterially induced membrane ruffles corresponding to invasion sites (Fig. 2g and Supplementary Fig. S8; 363 cells, $N=20$ ). Consistently, RATPs were associated with actin-rich membrane ruffles (Fig. 2g,h).

Restricted diffusion of small solutes at Shigella actin foci. In other systems, the extent of diffusibility of integral membrane proteins was shown to regulate $\mathrm{Ca}^{2+}$ signalling and phagocytic processes 27,28 . During Shigella invasion, the unusually long duration of RATPs suggested that diffusion of signals was 
a

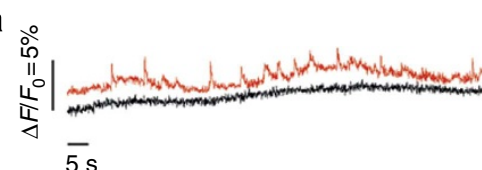

C

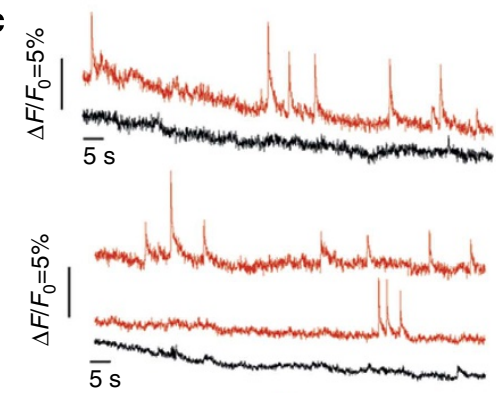

e

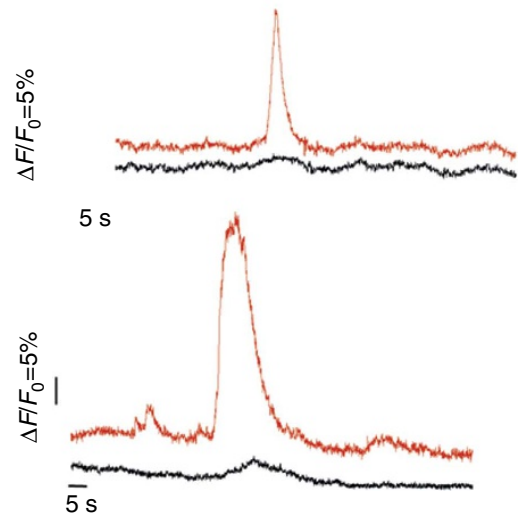

g

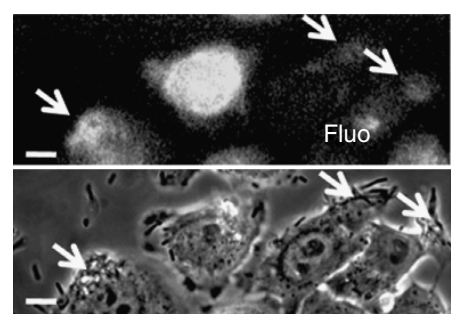

b

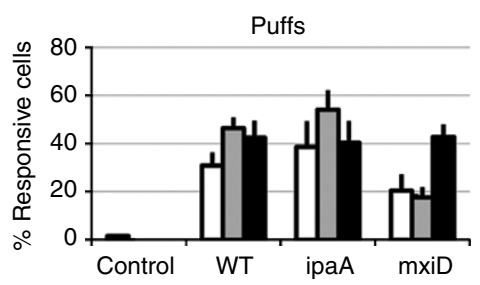

d

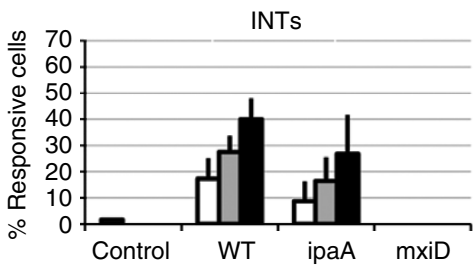

$\mathbf{f}$

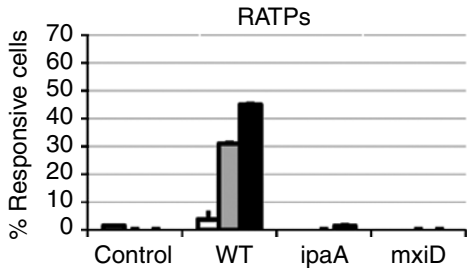

h
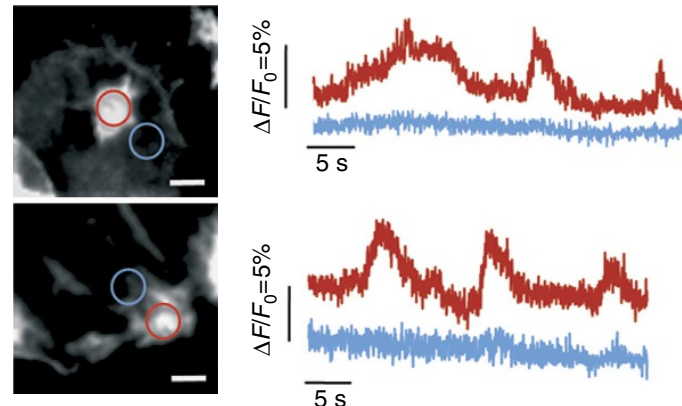

Figure 2 | Shigella induces long-lasting local $\mathbf{C a}^{2}+$ responses associated with invasion sites. HeLa cells challenged with Shigella strains and analysed by HSFM. (a,c,e) Each set of traces correspond to local variations of intracellular $\mathrm{Ca}^{2}+$ in the same cell. 'Puff-like' (a) or INT responses (c) induced by ipaA mutant; (e) RATP responses induced by wild-type (WT) Shigella. (b,d,f) Percentage of cells \pm s.e.m showing puff (b), INT (d) or RATP (f) responses at 5 (empty bars), 10 (grey bars) and $15 \mathrm{~min}$ (solid bars) following bacterial challenge. Unstimulated cells (control, 37 cells, $N=4$ ), or cells challenged for 5,10 or 15 min with WT $(52,58$ and 40 cells, respectively, $N=4)$, ipaA mutant $(57,61$ and 67 cells, respectively, $N=5)$ or mxiD mutant $(44,51$ and 43 cells, respectively, $N=3$ ). (g,h) Cells challenged with WT Shigella. Arrows, RATPs; (G, bottom), phase contrast; Fluo, Fluo-4 fluorescence. (h) F-actin staining (left panels) and local $\mathrm{Ca}^{2}+$ responses associated with bacterially induced foci (red traces) or control area (blue traces). Scale bar, $5 \mu \mathrm{m}$.

restricted in the cytosolic locale corresponding to bacterial entry sites. To test this, cells were loaded with the freely diffusible dye calcein and challenged with Shigella. Bacterially induced actin foci, readily observed in calcein-loaded cells, were subjected to fluorescence recovery after photo-bleaching (FRAP) analysis and HSFM $^{29}$ (Fig. 3a,b). The diffusion rate in Shigella foci was remarkably conserved in the various determinations, with a halfmaximal recovery rate $t_{1 / 2}=302 \pm 14 \mathrm{~ms}$ (Table 1 and Fig. $3 \mathrm{~d}$ ). This value was significantly higher than the $t_{1 / 2}=187 \pm 9 \mathrm{~ms}$ determined in control area corresponding to the free diffusion of calcein in the cell cytosol (Table 1). Addition of $0.5 \mu \mathrm{M}$ cytochalasin $\mathrm{D}$ or $2 \mu \mathrm{M}$ latrunculin $\mathrm{B}$, which block actin polymerization, led to the rapid disorganization of bacterially induced actin foci, with the disappearance of large actin-rich ruffles and the dense actin meshwork contacting bacteria (Fig. 3e). Consistent with actin filaments restricting diffusion at
Shigella-invasion sites, FRAP analysis of cytochalasin D- or latrunculin B-treated foci indicated $t_{1 / 2}$ of $246 \pm 14 \mathrm{~ms}$ (Table 1) and $202 \pm 10 \mathrm{~ms}$ ( 25 foci, $N=3$ ), respectively. These values were significantly lower than those obtained for foci induced by wild-type Shigella in untreated samples with $P=0.0117$ for cytochalasin- and $P=0.0126$ for latrunculin-treated cells when tested with an unpaired Student's $t$-test with unequal variance.

Because of the small size of the calcein tracer, its restriction of diffusion is unlikely due to a 'sizing' effect, but rather to a 'crowding' effect of the actin meshwork described elsewhere for the diffusibility of cytosolic proteins ${ }^{29,30}$, which could be viewed as a lengthening of the trajectories that have to be covered by the particles through the meshwork. Because our findings suggested that such a 'crowding' effect also applied to small molecules, we extended these FRAP experiments to different size fluorescent tracers. Cells were microelectroporated with fluorescent ATP 


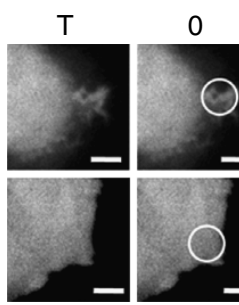

b
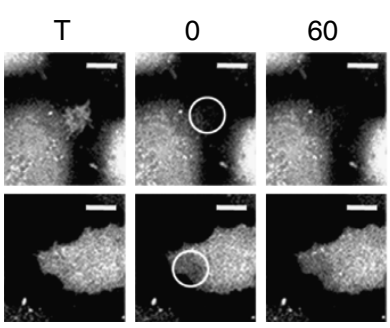

C

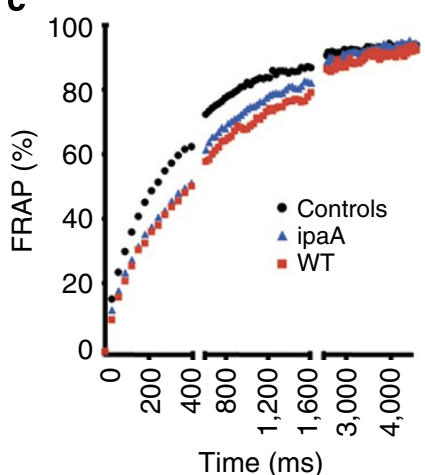

60

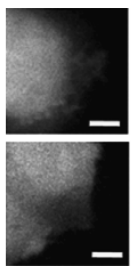

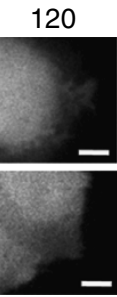
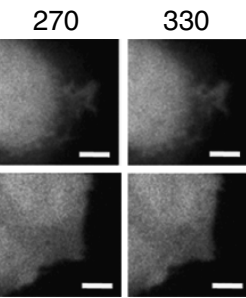

360
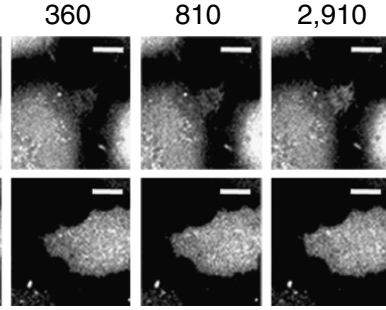

d

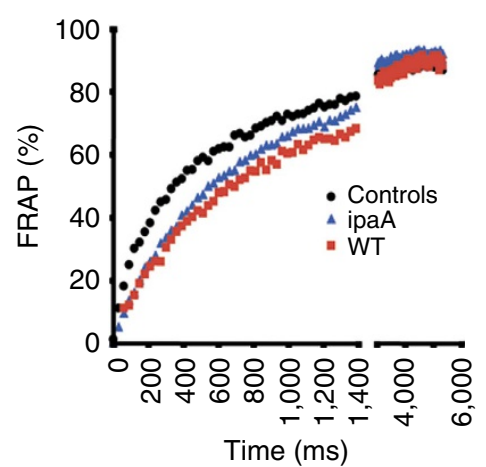

e
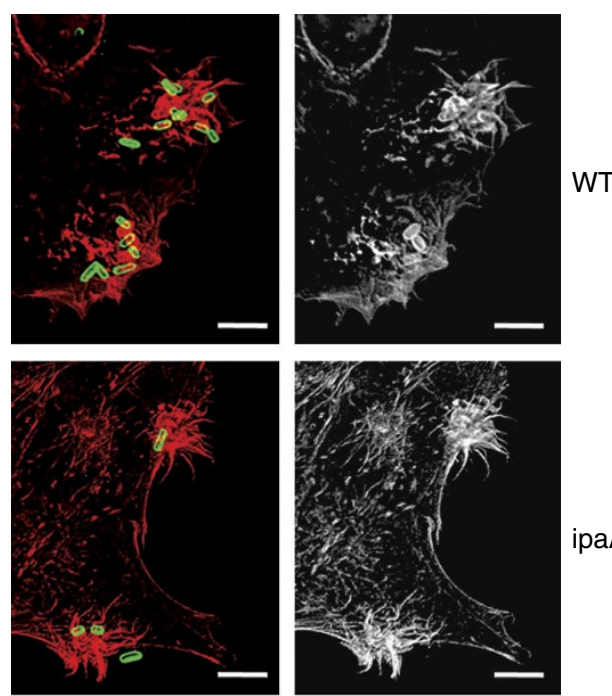

ipaA
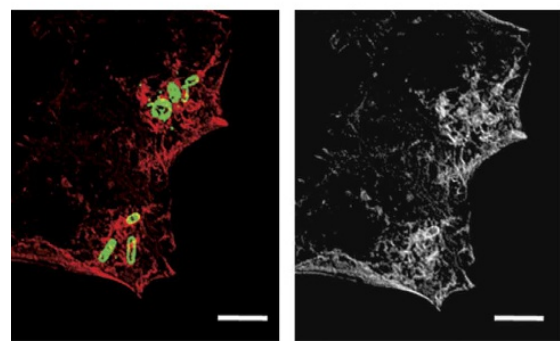

WT + cytD

Figure 3 | Restriction of diffusion in Shigella-invasion foci. (a-d,f) FRAP analysis of Shigella-invasion foci. (a,b) Representative time-lapse images of invasion foci (top panels) or control (bottom panels). Empty circle, bleached area. The time after bleach is indicated in ms for cells loaded with calcein $(\mathbf{a}, \mathbf{c})$ or fATP $(\mathbf{b}, \mathbf{d})$. (c,d) Fluorescence recovery kinetics in \%; black, control area; foci induced by wild-type (WT) Shigella (red) or ipaA mutant (blue). Broken time scales are depicted to better show differences between kinetics. (e) Staining of F-actin (red and grey levels) and bacterial lipopolysaccharide (green) of foci induced by: + CytD, with cytochalasin D; ipaA: ipaA mutant. Scale bar, $5 \mu \mathrm{m}$.

Table 1 | Half-maximal recovery values from FRAP experiments indicate restricted diffusion in Shigella-induced foci

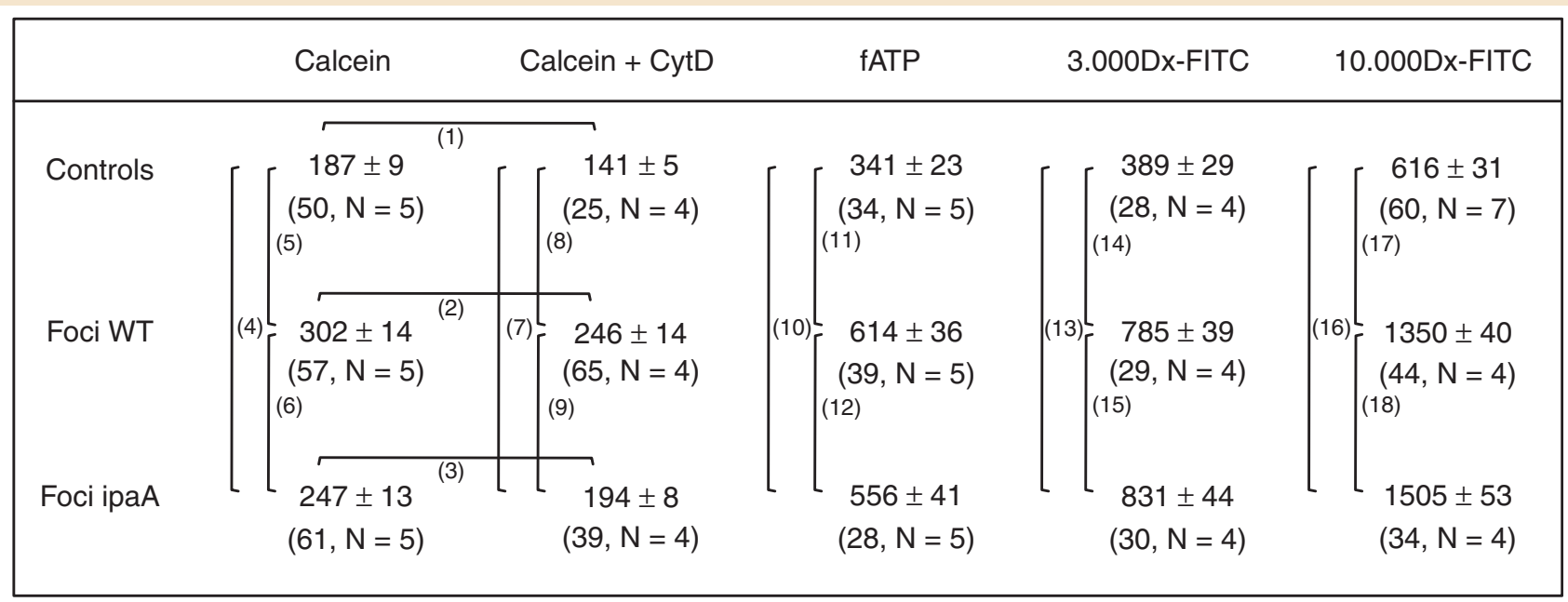

Half-maximal recovery values were determined from fits \pm s.e.m. for the indicated samples with or without $0.5 \mu \mathrm{M}$ cytochalasin D. The number of determinations and independent experiments are indicated below the values. Statistical significance between values annotated by numbers between small brackets was tested using an unpaired Student's $t$-test with unequal variance. The obtained $P$-value were as follows: (1): 0.0043; (2): 0.0117; (3): 0.0141; (4): 0.0053; (5): 0.0001; (6): 0.0205; (7): 0.0014; (8): 0.0004; (9): 0.018; (10): 0.0018; (11): 0.0002; (12): 0.3188; (13): 0.0002; (14): 0.0002 ; (15): 0.4637; (16): 0.0001; (17): 0.0001; (18): 0.058, with $P>0.05$ considered as non-significant. 
a

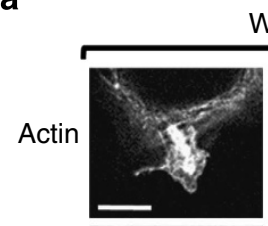

WT
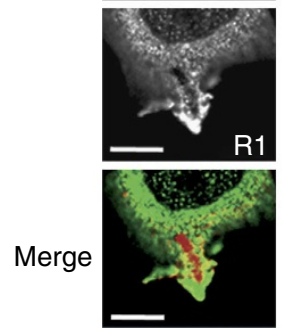

sa

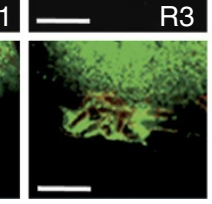

d

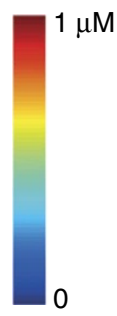

(1)

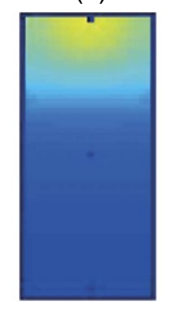

(2)

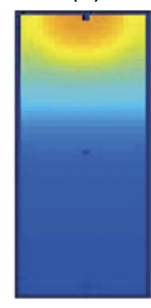

ipaA

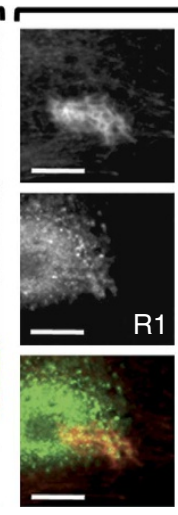

(3)

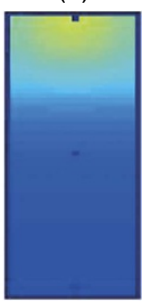

e b
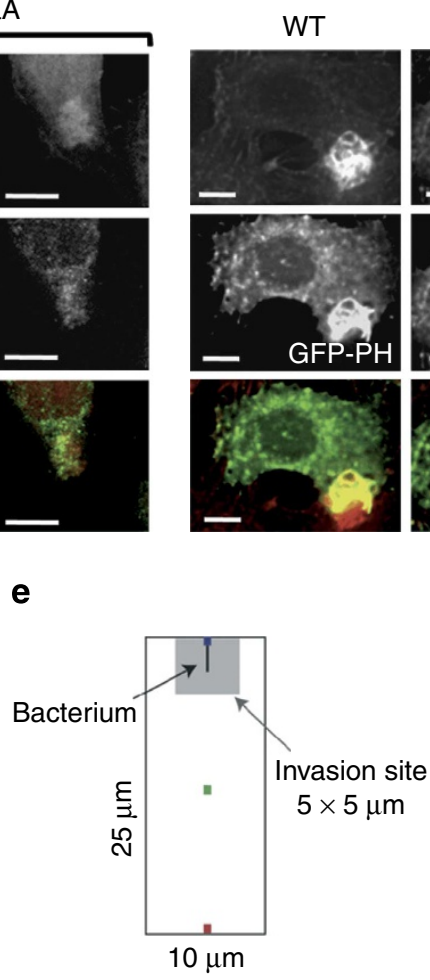

c
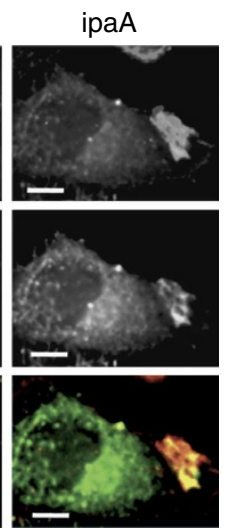

WT

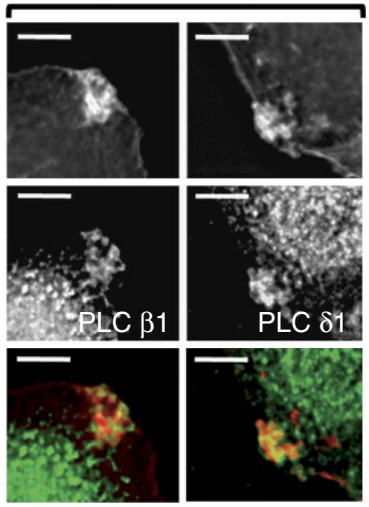

f

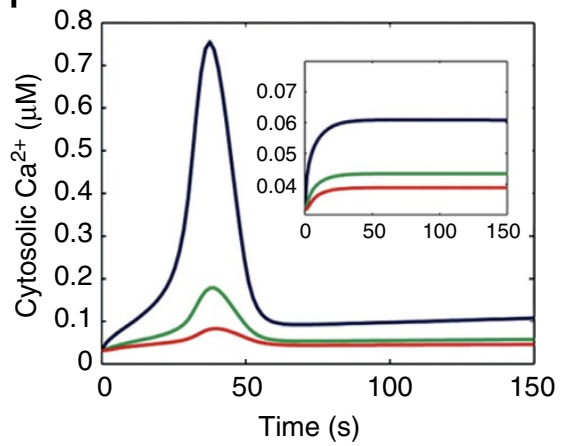

Figure 4 | Enrichment of InsP3-signalling components and simulations of local $\mathbf{C a}^{2}+$ increases at Shigella-invasion sites. (a-c) Fluorescence micrographs of invasion foci induced by wild-type (WT) Shigella or ipaA mutant as indicated. Top panels: F-actin; middle panels: InsP $\mathrm{P}_{3} \mathrm{R} 1$ (a, R1) or InsP $\mathrm{A}_{3} \mathrm{R}$ (a, R3), GFP-PH $\mathrm{PLC}-\delta 1_{1}(\mathbf{b})$, or PLC- $\beta 1$ (c) left), PLC- $\delta 1^{\prime}$ (c), right). (d) Simulated levels of cytosolic $\mathrm{Ca}^{2+}$ at 35 (1), 40 (2) and $45 \mathrm{~s}(3)$ after the onset of bacterial invasion depicted in colour scale with dark blue and red corresponding to 0 and $1 \mu \mathrm{M}$, respectively. (e) Schematic representation of the system simulated in $\mathbf{d}$. For integration, the system is divided in $60 \times 24$ mesh points, indexed by $i$ and $j$, respectively. In the region $i=1-12$ and $j=6-19, D_{C}$ and $D_{\mathrm{l}}$ are divided by 1.6 and $k_{1}$ is multiplied by 3 . $J_{\mathrm{IP}}$ is equal to $15 \mu \mathrm{Ms}^{-1}$ for $\mathrm{i}=1-7$ and $\mathrm{j}=11-13$, and 0 everywhere else. (f). Evolution of $\mathrm{Ca}{ }^{2}+\mathrm{concentrations}$ at the upper (invasion site) (blue), medium (green) and lower (red) point in (1)-(3). Inset: simulations performed without restricted diffusion (see Methods).

(fATP), 3 or $10 \mathrm{kDa}$ dextrans in cells before infection and FRAP analysis (Methods). This analysis confirmed restriction of diffusion in invasion foci, which was more pronounced with higher molecular weight tracers, with up to a 2.5-fold difference in the $t_{1 / 2}$ for the $10 \mathrm{kDa}$ fluorescein isothiocyanate (FITC)-conjugated dextran (FITC-dextran) between entry foci compared with the cytosol control (Table 1, Fig. 3d and Supplementary Fig. S9).

Shigella actin foci as local source of Ins $P_{3}$ production. We then investigated how actin-based diffusion hindrance could shape Ins $\mathrm{P}_{3}$-dependent signalling and create RATPs at Shigella-invasion sites. We first wanted to determine whether Shigella-induced foci corresponded to local sources of $\mathrm{Ins}_{3}$ production, based on the recruitment of $\mathrm{Ins}_{3}$-signalling component. Among the phospholipase Cs (PLCs) expressed in HeLa cells, PLC- $\beta 1$ and PLC- $\delta 1$ were found to be recruited at Shigella-induced foci (Fig. 4c, Supplementary Fig. S10 and S11). Cell treatment with shRNAs against PLC- $\beta 1$ and PLC- $\delta 1$ resulted in a $38 \%$ decrease in foci formation, indicating their implication in Shigella-induced cytoskeletal reorganization (Supplementary Fig. S9). Consistent with PLC activation and local $\mathrm{Ins}_{3}$ production, Shigella-induced foci were strongly labelled with a GFP-PH $\mathrm{PLC}_{-\delta 1}$ probe for $\mathrm{InsP}_{3}$ (ref. 31) (Fig. 4b). When quantified, the enrichment of these Ins $\mathrm{P}_{3}$-signalling components ranged between 1.7 and 2.5 fold the average levels observed in the cell ( $>50$ foci, $N=3$; Methods; Fig. 4 and Supplementary Fig. S11). No significant difference could be detected between enrichment observed in foci induced by wild-type Shigella and the ipaA mutant, indicating the bacterially induced $\mathrm{InsP}_{3}$ signalling occured independent of this T3SS-injected effector (Fig. 4a and Supplementary Fig. S11C). Similarly, actin foci induced by other Shigella mutants deficient for the T3SS-injected invasion effectors IpaA, IpgB1 and IpgD still showed enrichment of $\mathrm{InsP}_{3} \mathrm{R} 1$ (Fig. 4 and Supplementary Fig. S12). In contrast, such $\mathrm{Ins}_{3} \mathrm{R} 1$ enrichment was not observed for T3SS-deficient mxiD mutant, or translocator componentdeficient $i p a B$ or ipaC mutants (Supplementary Fig. S12). These results suggested that $\mathrm{Ins}_{3} \mathrm{Rs}$ enrichment at bacterial invasion sites were induced by the T3SS translocator components at the plasma membrane, presumably following local activation of a PLC and $\mathrm{Ins}_{3}$ production. Together, these data support the notion that Shigella-invasion sites correspond to local sources of Ins $\mathrm{P}_{3}$ production, enriched in $\mathrm{Ins}_{3}$-signalling components.

Modelling Shigella-induced long-lasting local $\mathrm{Ca}^{2+}$ responses. We then resorted to theoretical modelling to apprehend how, from the bacterial point source of $\mathrm{InsP}_{3}$ synthesis, the restricted diffusion could shape localized $\mathrm{Ca}^{2+}$ responses with long duration, such as RATPs, despite the high diffusivity of $\mathrm{Ca}^{2+}$ and $\mathrm{InsP}_{3}$. We first analysed spatial inhomogeneities in $\mathrm{InsP}_{3}$ 
signalling. Based on our results, we postulated that PLC activation at the site of contact between the bacterium and the cell plasma membrane stimulated localized InsP $\mathrm{P}_{3}$ synthesis in a $2.5 \times 1.2 \mu \mathrm{m}^{2}$ region inside the actin focus, represented as a $5 \times 5 \mu \mathrm{m}^{2}$ region in the simulated $25 \times 10 \mu \mathrm{m}^{2}$ cell (Supplementary Fig. S13A). We assigned a value for the $\mathrm{InsP}_{3}$ diffusion coefficient 1.6 times lower in the actin focus than in the remaining cytoplasm. This 1.6 times decrease in the diffusion coefficient at bacterial invasion sites was based on the value that we determined for the freely diffusible dye calcein, and may correspond to an underestimation of the decreased diffusibility of $\mathrm{Ins}_{3}$, likely to be further restricted by interactions with $\mathrm{InsP}_{3}$-signalling components observed in Fig. 4a-c. Indeed, fATP, which may present diffusion characteristics closer to those of $\operatorname{InsP}_{3}$, showed a 1.8 decrease in diffusion in Shigella-invasion sites compared with the control cell area.

Our simulations, taking into account a stimulated rate of $\operatorname{Ins}_{3}$ synthesis of $15 \mu \mathrm{Ms}^{-1}$ and the 1.6 -fold restriction of diffusion observed at Shigella-invasion sites, indicated the presence of a gradient of InsP $\mathrm{P}_{3}$ from the source of PLC-activation site corresponding to the bacterial site of contact with the cell membrane. This gradient was maintained throughout the duration of $\operatorname{Ins}_{3}$ synthesis (Supplementary Fig. S13B). According to the model, a modest gradient in $\mathrm{Ins}_{3}$ concentration resulted in a pronounced gradient in $\mathrm{Ca}^{2+}$ release when combined to the observed accumulation of $\mathrm{InsP}_{3}$ receptors at the invasion site (Supplementary Fig. S13C). This enhanced $\mathrm{Ca}^{2+}$ release could in turn be responsible for RATPs. We thus modelled the spatio-temporal evolution of $\mathrm{Ca}^{2+}$ concentration by simulating the activity of $\mathrm{InsP}_{3}$ receptors and concentrations of $\mathrm{Ca}^{2+}$ and $\mathrm{InsP}_{3}{ }^{32}$ (Methods). Besides a classical description of InsP $\mathrm{P}_{3}$-mediated $\mathrm{Ca}^{2+}$ exchanges between the cytoplasm and the intracellular pools, the model took into account-specific features related to Shigella invasion: the reduced diffusivity, the higher density of InsP $\mathrm{P}_{3}$ receptors in actin foci and the stimulation of PLC activity at the invasion site.

As shown in Fig. 4d-f, confined RATP-like responses lasting for up to $20 \mathrm{~s}$ were simulated under these conditions. The synergistic effect of reduced diffusion and receptor enrichment relied on the highly non-linear nature of $\mathrm{InsP}_{3}$-induced $\mathrm{Ca}^{2+}$ release, due to its self-amplification through $\mathrm{Ca}^{2+}$-induced $\mathrm{Ca}^{2+}$ release $^{33}$. As schematized in Supplementary Fig. S13B, S13C, slight variations of $\mathrm{Ins}_{3}$ levels were further amplified at the levels of $\mathrm{Ca}^{2+}$ concentrations, through the inhomogeneous density of InsP ${ }_{3} R s$ and the intrinsic steep dependence of the activity of this channel on $\mathrm{Ins}_{3}$ concentration (Supplementary Fig. S13C). This mechanism for RATPs occurrence predicted by our phenomenological model was robust with respect to changes in parameter values and in agreement with the observed absence of $\mathrm{Ca}^{2+}$ responses in cells overexpressing $\mathrm{InsP}_{3}-5$ phophatase or incubated in a $\mathrm{Ca}^{2+}$-free medium. Simulations performed with a 1.8 instead of a 1.6 decrease in the diffusion coefficient of $\mathrm{InsP}_{3}$ parameter led to RATPs with similar durations, but with 1.25 -fold increase in $\mathrm{Ca}^{2+}$ concentrations at Shigella-invasion sites. Thus, the value of the diffusion coefficient in the actin focus controls both the amplitude of the $\mathrm{Ca}^{2+}$ increase and the delay between invasion and RATP occurrence. These results, taking into account diffusion parameters falling in the range of what we experimentally determined for small molecules at invasion sites, are in line with the amplitude of RATPs experimentally observed during Shigella invasion. An interesting prediction of the computer simulations is that both inhomogeneities in $\mathrm{InsP}_{3}$ and InsP ${ }_{3}$ Rs levels in the actin foci need to be linked to get the localized sustained $\mathrm{Ca}^{2+}$ responses. Indeed, if diffusion was not restricted (Fig. 4f, inset), no significant local $\mathrm{Ca}^{2+}$ increase was observed.
INTs and diffusion in Shigella ipaA-mutant actin foci. We then wanted to test the predicition of our model establishing a critical role of the actin meshwork-based diffusion restriction on the elicitation of RATPs at bacterial invasion sites. For this, cells were challenged with an ipaA mutant, which induces actin foci at the same frequency than wild-type Shigella, but fails to organize a dense actin meshwork in close apposition to bacteria and invades cell inefficiently ${ }^{8,9}$ (Fig. 3e). Consistent with an absence of role of IpaA in the initial steps of invasion leading to bacterially induced actin polymerization, InsP $\mathrm{P}_{3}$ and $\mathrm{InsP}_{3} \mathrm{Rs}$ were osberved to accumulate at actin foci induced by an ipaA mutant to a similar extent than in foci induced by wild-type Shigella (Fig. 4a and Supplementary Fig. S11). Remarkably, however, FRAP analysis indicated that foci induced by the ipaA mutant showed faster diffusion rates than those induced by wild-type Shigella, with an average $t_{1 / 2}=247 \pm 13 \mathrm{~ms}$ ( $61 \mathrm{foci}, N=4$ ). Because the effects of IpaA on actin reorganization at Shigella-invasion sites are mediated by its ability to bind to and to activate the focal adhesion protein vinculin, permitting the remodelling of actin filaments at bacterial invasion sites, these results further support the notion that actin filaments' organization restricted diffusion at Shigella entry sites. Consistent with the notion that the restriction of diffusion at bacterial entry sites is critical for the duration of local $\mathrm{Ca}^{2+}$ responses, the ipaA mutant induced less INTs than wild-type Shigella, and virtually no RATPs (Fig. 1f,h). The recruitment of InsP $\mathrm{P}_{3} \mathrm{R} 1$ and GFP-PHPLC- $\delta 1$ in foci induced by the ipaA mutant at levels comparable to foci induced by wild-type Shigella suggested that the absence of RATPs in this mutant was linked to an altered actin meshwork and faster diffusion at the invasion sites (Fig. 4a,b), a situation that corresponds to the simulation shown in the inset of Fig. $4 \mathrm{f}$.

Mitochondrial activation at bacterial entry sites. Because $\mathrm{Ca}^{2+}$ is a key regulator of mitochondrial functions, we next wanted to test the consequences of RATPs on mitochondrial activation during Shigella invasion ${ }^{34,35}$. Although $\mathrm{Ca}^{2+}$ transients activate mitochondrial ATP synthesis, sustained mitochondrial $\mathrm{Ca}^{2+}$ increases lead to the loss of mitochondrial membranes integrity and the release of pro-apoptotic factors and cell death ${ }^{35}$. Interestingly, following prolonged incubation for several hours and intracellular multiplication, Shigella was shown to induce a necrotic-like cell death, linked to global $\mathrm{Ca}^{2+}$ influx and mitochondrial damage ${ }^{36}$. As shown in Fig. 5, mitochondria could be detected early during bacterial invasion, in Shigellainduced actin foci. Mitochondria were detected in all foci analysed, either at the close vicinity of invading bacteria or trapped in the actin meshwork induced by wild-type Shigella or the ipaA mutant (Fig. 5a,b). Confocal fluorescence microscopy analysis, however, indicated that $\mathrm{InsP}_{3} \mathrm{R} 1$ labelling in bacterially induced actin foci did not co-localize with mitochondria, suggesting that their presence implicated distinct processes (Supplementary Fig. S14). An expected consequence of RATPs would be a sustained activation of mitochondria at invasion sites. Mitochondria were detected at bacterial invasion sites, entrapped in bacterially induced polymerized actin (Fig. 5a). To follow changes in mitochondrial $\mathrm{Ca}^{2+}\left(\mathrm{Ca}^{2+}{ }_{\text {mito }}\right)$, cells were transfected with the fluorescence resonance energy transfer (FRET)-based sensor $4 \mathrm{mtD} 3 \mathrm{cpV}^{37}$. Upon challenge with Shigella, an increase in $\mathrm{Ca}^{2+}{ }_{\text {mito }}$ was observed in $94 \pm 9 \%$ of the foci analysed ( 35 foci, $N=7$ ). Moreover, as illustrated in Fig. $5, \mathrm{Ca}^{2+}{ }_{\text {mito }}$ increases at entry sites could occur independent of variations of $\mathrm{Ca}^{2+}{ }_{\text {mito }}$ in the rest of the cell, and like RATPs, could last several tens of seconds (Fig. 5c). When cells were challenged with the ipaA mutant, however, only $42 \pm 11 \%$ of bacterially induced foci were associated with an increase in 
a

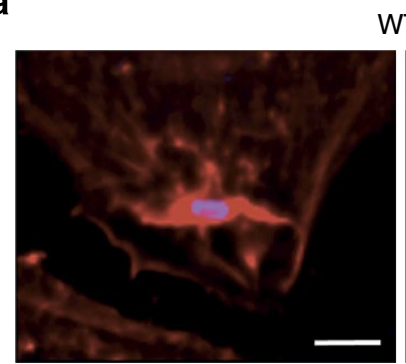

WT

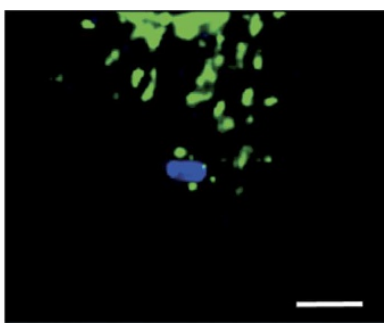

C
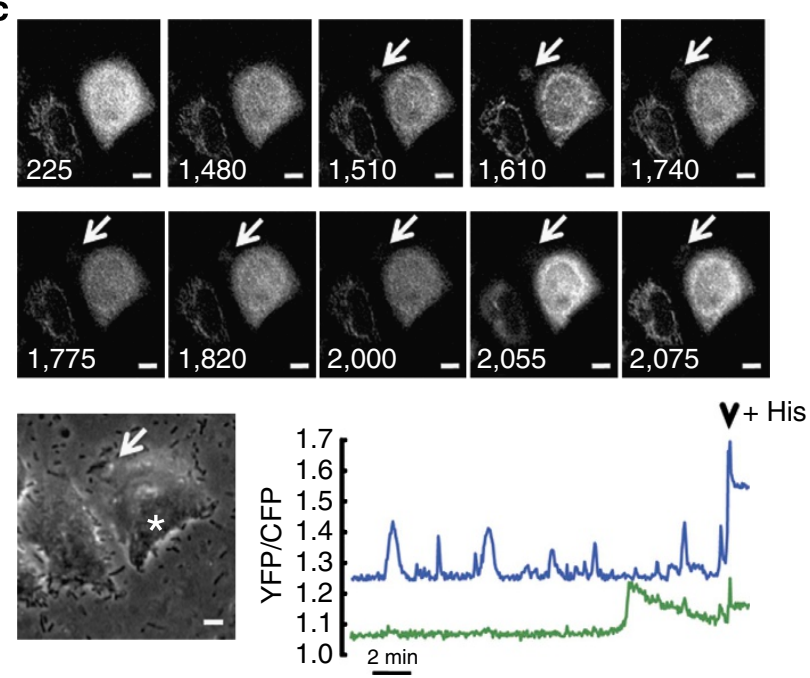

b

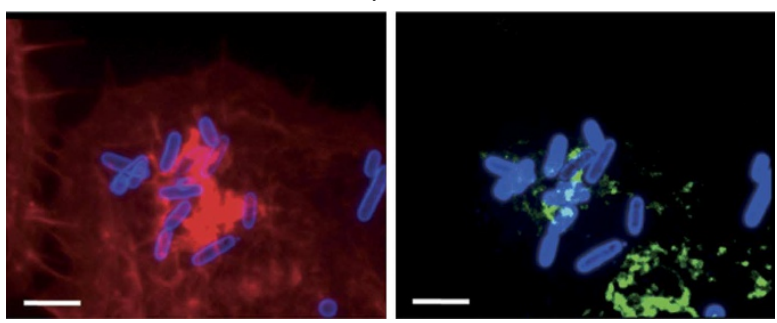

d
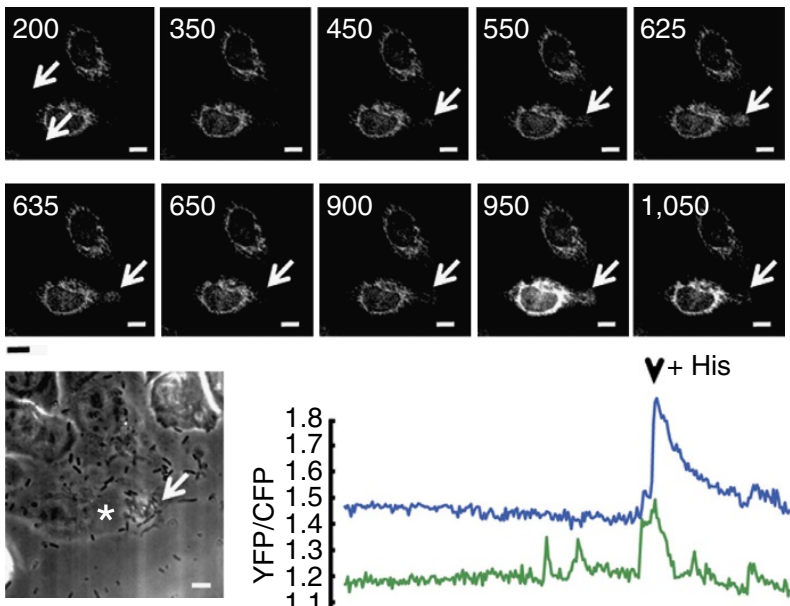

1,050
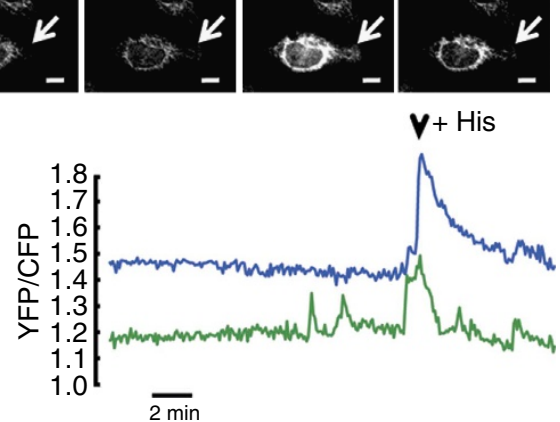

Figure 5 | Mitochondrial activation during Shigella invasion. Staining of F-actin (red) and bacterial lipopolysaccharide (blue) of cells transfected with 4mitD3cpv (green) challenged with wild-type (WT) (a) or ipaA-mutant Shigella (b). (c,d) Ratio images of citrine (YFP)/Cyan Fluorescent protein (CFP) emissions in time-lapse analysis of 4mitD3cpv-transfected cells challenged with WT Shigella (c) or the ipaA mutant (d). Time after challenge in ms. Arrows: invasion foci. Scale bar, $5 \mu \mathrm{m}$. Traces: average intensity in invasion foci (green) or control area (blue). Arrowheads: addition of $20 \mu \mathrm{M}$ histamine (His).

$\mathrm{Ca}^{2}+{ }_{\text {mito }}(31$ foci, $N=5)$. Furthermore, foci induced by the ipaA strain were seldom associated with long-lasting $\mathrm{Ca}^{2+}{ }_{\text {mito }}$ increases, consistent with the low frequency of RATPs induced by this mutant (Fig. 5d).

As opposed to long-term bacterial infection, however, mitochondrial swelling could be not detected at early time points of infection ${ }^{36}$, suggesting that local and prolonged increases in mitochondrial $\mathrm{Ca}^{2+}$ did not induce mitochondrial dysfunction. To confirm this, we used the $F_{1} / F_{0}$ ATP synthase inhibitor oligomycin $\mathrm{A}^{38}$ to determine the contribution of mitochondrial ATP in our experimental conditions. Dosage of cytosolic ATP levels indicated that mitochondrial ATP synthase activity accounted for $85 \%$ of the total ATP levels (Supplementary Fig. S15). Furthermore, Shigella invasion resulted in a $10-20 \%$ depletion of global ATP pools, indicating that bacterial invasion did not result in a general mitochondrial dysfunction (Supplementary Fig. S15). These results are in line with the notion that the confinement of sustained local $\mathrm{Ca}^{2+}$ responses allow the prolonged activation of mitochondria at invasion sites.

\section{Discussion}

To enter efficiently into cells, Shigella needs to establish a dense meshwork of actin filaments at the plasma membrane-bacterial contact site, which is allowed by the vinculin-binding type III effector IpaA. Here we bring evidence that this actin meshwork limits diffusion of free solutes, probably by creating mechanical obstructions as reported in other systems ${ }^{29,30}$. We propose that during Shigella invasion, the local activation of PLC- $\beta 1$ and $-\delta 1$ leads to accumulation of $\operatorname{Ins}_{3}$ at invasion sites (Supplementary Fig. S16). InsP ${ }_{3} \mathrm{Rs}$ enriched at bacterially induced actin foci, possibly through a diffusion-capture process involving $\mathrm{InsP}_{3}$ binding or through interaction with a cytoskeletal protein such as band 4.1 (ref. 39), shown critical for bacterial invasion. Previous studies have reported that Puffs elicited by $\mathrm{InsP}_{3}$ (ref. 40) stimulation could originate from pre-clustered InsP3Rs, or alternatively, implicated the de novo clustering of $\operatorname{InsP}_{3} \mathrm{Rs}^{41}$. Although we observed Puff-like responses elicited early upon bacterial challenge, these did not appear specific for bacterial invasion. In contrast, RATPs at bacterially induced foci were associated with a massive recruitment of Ins $\mathrm{P}_{3} \mathrm{Rs}$, which could either result from Ins $\mathrm{P}_{3}$-mediated clustering of Ins $\mathrm{P}_{3} \mathrm{Rs}$ or, given the extended kinetics of the invasion process, possibly through the recruitment of pre-clustered Ins $_{3}$ Rs at Shigella-invasion sites. As modelled in this study, restricted diffusion is critical for the elicitation of sustained local $\mathrm{Ca}^{2+}$ increases at entry sites (Supplementary Fig. S16). There are multiple implications of long-lasting local $\mathrm{Ca}^{2+}$ responses during Shigella invasion. RATPs will regulate the function of $\mathrm{Ca}^{2}{ }^{+}$-dependent enzymes, which may have an impact on cytoskeletal reorganization at the site of bacterial invasion. For example, calpains, whose proteolytic activity is $\mathrm{Ca}^{2+}$ dependent, have been implicated in Shigella invasion $^{42}$. Also, myosin II, whose activity is regulated by $\mathrm{Ca}^{2+}$, has been implicated in Salmonella invasion, a process sharing similarities with Shigella invasion ${ }^{43}$. The confinement of RATPs at invasion sites may also allow to limit the spreading of apoptotic signals linked to prolonged elevated mitochondrial $\mathrm{Ca}^{2}+$ during the early stages of infection. Mitochondrial activation through Ins $\mathrm{P}_{3}$-mediated $\mathrm{Ca}^{2}+$ increase allows ATP production through 
oxidative phosphorylation ${ }^{34}$. Interestingly, local ATP supply was shown critical for cytoskeletal remodelling processes requiring high energy during phagocytosis, a process sharing similarities with Shigella invasion ${ }^{44}$. In future work, it will be interesting to determine if mitochondria favour bacterial invasion, by allowing the local production of ATP required for elongation of actin filaments.

\section{Methods}

Antibodies and reagents. The rabbit polyclonal antibody against the type 1 InsP3 receptor (ABR Affinity Bioreagents) and the mouse monoclonal antibody against type $3 \mathrm{InsP}_{3}$ receptor (Transduction laboratories) were both used at a dilution of 1:1,000 and 1:100 for western blot and immunofluorescence analysis, respectively. The sarco/endoplasmic reticulum $\mathrm{Ca}^{2+}$-ATPase (SERCA) inhibitor tBuBHQ, the $\mathrm{F}$-actin inibitors cytochalasin D and latrunculin B were from Sigma-Aldrich. The anti-lipopolysaccharide polyclonal $\mathrm{Ab}$ was described previously and was used at a 1:1000 dilution ${ }^{28} \cdot \gamma$-(6-Aminohexyl)-ATP-Atto488 (fATP) was from Jena Biosciences. Calcein-AM, FITC-dextrans ( 3 and $10 \mathrm{kDa}$ ), Phallicidin-A488, antirabbit IgG-A547 and the fluorescent $\mathrm{Ca}^{2+}$ probes, Fluo-4-AM, Fura-Red-AM and Fura-2-AM, were from Invitrogen Corp. siRNAs against the type 1 and type 3 $\mathrm{Ins}_{3}$ receptors were from Qiagen.

Cell lines, bacterial strains and plasmids. The wild type Shigella serotype $\mathrm{V}$ M90T and its isogenic derivatives $m x i D$ and $i p a A$ were described previously ${ }^{45}$. Bacteria were grown in trypticase Soy broth at $37^{\circ} \mathrm{C}$ in a shaking incubator. HeLa cells were from ATCC. HCx26 cells were described previously ${ }^{3}$. All cells were grown in RPMI medium containing 5\% fetal calf serum in a $5 \% \mathrm{CO}_{2}$ incubator. The plasmid encoding the genetically encoded mitochondrial $\mathrm{Ca}^{2+}$ FRET sensor 4 mitD3cpv was described previously ${ }^{46}$. The gene encoding the type $\mathrm{I} \mathrm{InsP}_{3}-5^{\prime}$ phosphatase was retrieved by KpnI and EcoRV digestion from the previously described clone $\mathrm{D} 1^{25}$ and subcloned, after a T4 DNA polymerase treatment into the pIRES-GFP vector (Clontech) using the Eco47III restriction enzymes to generate pIRES-InsP ${ }_{3}-5 \mathrm{P}-\mathrm{GFP}$. Constructs were checked by DNA sequencing. Cells were transfected with plasmid constructs using JetPei (Polyplus) or with anti$\mathrm{InsP}_{3} \mathrm{R}$ siRNA using the HiPerfect transfection reagents (Invitrogen) following the manufacturer's instructions.

Immmunofluorescence analysis of Shigella-induced actin foci. Shigella-induced actin foci of invasion were scored as described previously ${ }^{6}$. When mentionned oligomycin A was added at a final concentration of 5 or $10 \mu \mathrm{g} \mathrm{ml}^{-1}$ for $16 \mathrm{~h}$ at $37^{\circ} \mathrm{C}$ before bacterial challenge.

Statistical analysis. For all samples, significance relative to control samples was tested using an unpaired Student's $t$-test with unequal variance unless otherwise stated.

Calcium fluorescence microscopy imaging. Analysis of global $\mathrm{Ca}^{2+}$ variation was performed by loading cells with $3 \mu \mathrm{M}$ Fura-2-AM in EM buffer containing $120 \mathrm{mM} \mathrm{NaCl}, 7 \mathrm{mM} \mathrm{KCl}, 1.8 \mathrm{mM} \mathrm{CaCl} 2,0.8 \mathrm{mM} \mathrm{MgCl} 2,5 \mathrm{mM}$ glucose and $25 \mathrm{mM}$ HEPES pH 7.3, as described previously ${ }^{3}$. For high-speed analysis of local $\mathrm{Ca}^{2+}$ variations, cells were loaded with $3 \mu \mathrm{M}$ Fluo-4-AM. Samples were analysed at $33^{\circ} \mathrm{C}$ on an inverted Leica DMRIBe fluorescence microscope, equiped with light-emitting diode $470 \mathrm{~nm}$ illuminating sources and a $480 \mathrm{~nm}$ band pass excitation filter, a $505 \mathrm{~nm}$ dichroic filter and a 527-band pass emission filter driven by the Metamorph software from Roper Scientific Instruments. Images were captured using a Cascade 512B EM-CCD back-illuminated camera in a stream mode, with an acquisition every $30 \mathrm{~ms}$. Changes in the ratio of Fura-2 $(\Delta R)$ or Fluo-4 fluorescence intensity $(\Delta \mathrm{F})$ were calculated relative to the resting ratio or fluorescence value $\left(R_{0}\right.$ or $\left.\mathrm{F}_{0}\right)$ as $\Delta R / R_{0}$ or $\Delta \mathrm{F} / \mathrm{F}_{0}$, respectively. Cells showing local $\mathrm{Ca}^{2+}$ responses were scored by High Speed Fluorescence Microscopy (HSFM). The average percentage of responsive cells showing at least a detectable $\mathrm{Ca}^{2+}$ response during the length of the analysis was determined. The amplitude of local responses corresponded on average to $6.9 \pm 0.6(N=16)$ and $55 \pm 6 \%(N=12)$ of the maximal response obtained using histamine as an agonist at the maximal concentration of $30 \mu \mathrm{M}$, for puff-like and RATP responses, respectively.

To monitor variations in mitochondrial $\mathrm{Ca}^{2+}$, cells transfected with the 4 mitD3cpv construct were analysed using a dichroic 455DRLP, and the following filters: $450 \mathrm{~nm}$ excitation and $490 \mathrm{~nm}$ emission filters for cyan fluorescent protein (CFP), 490/40 nm excitation and 535/40 nm emission filters for citrine, and $450 \mathrm{~nm}$ excitation and 535/40 nm emission filters for the FRET image. All images were corrected for background fluorescence.

Calcein loading and FRAP analysis. Cells grown on cover slips were loaded with $3 \mu \mathrm{M}$ calcein-AM by incubation in EM buffer or, alternatively, by microelectroporation for fATP, $3 \mathrm{kDa}$ - and $10 \mathrm{kDa}$ dextran-FITC (Supplementary Information). Samples were mounted in an observation chamber on a plate heated at $37^{\circ} \mathrm{C}$ on an inverted spinning disk confocal microscope (Nikon Eclipse Ti) analysed with a $\times 60$ objective lens, using an EM-CCD camera Evolve equipped with a FRAP module and driven by the Metamorph software (Roper Scientific Instruments), allowing the acquisition of images during the bleaching phase. Samples were challenged with Shigella strains at a multiplicity of infection of 5-10 (final $\mathrm{OD}_{600 \mathrm{~nm}}=0.1$ ) for $15 \mathrm{~min}$. For each samples, bleaching and image acquisition were performed using identical conditions, with the exception of the bleach area defined to encompass bacterial invasion foci. Variations in the bleach area size, however, did not exceed $10 \%$ between all samples. An area of an average size \pm s.e.m. of $24.2 \pm 0.7 \mathrm{~mm}^{2}$, corresponding to the bacterial invasion foci, was bleached using a $470 \mathrm{~nm}$ excitation laser for $80 \mathrm{~ms}$ until fluorescence was reduced to background levels. For each experiment, an area identical to the bacterial foci area was bleached in another cell in the same field. Image acquisition was performed under the stream mode every $30 \mathrm{~ms}$, with 200 frames during pre-bleach and 2,000 frames to monitor fluorescence recovery. Relative fluorescence intensity was determined as FRAP\% $=\left(\mathrm{F}_{\mathrm{t}} / \mathrm{C}_{\mathrm{t}}\right) /\left(\mathrm{F}_{0} / \mathrm{C}_{0}\right) \times 100$, where $\mathrm{F}_{0}$ and $\mathrm{C}_{0}$ represent the intensity of the bleached and control unbleached regions, respectively, before bleaching, and $\mathrm{F}_{\mathrm{t}}$ and $\mathrm{C}_{\mathrm{t}}$ represent the intensity at time $t$ after bleaching for the same corresponding regions. Fluorescence recovery curves corresponding to the normalized intensity in the bleached area averaged from several measurements showed good quality fit with a single-component diffusion ( $>32$ foci, $N=6$ ).

Immunofluorescence staining. Immunofluorescence analysis was performed as described previously ${ }^{7}$. Stacks of focal planes spaced by $0.2 \mu \mathrm{m}$ were processed for point spread function (PSF)-based three-dimensional deconvolution in the Metamorph software 7 or 4 (Universal Imaging) using a fast algorithm. Reconstructions were obtained by applying the average function on the stacks of deconvolved images.

Modelling. The site of bacterial invasion, modelled as a $5 \times 5 \mu \mathrm{m}^{2}$ region located at the upper, central part or the cell, shows reduced diffusibility, with $\operatorname{InsP}_{3}$ and $\mathrm{Ca}^{2+}$ diffusion coefficients 1.6 times smaller than that in the rest of the cytoplasm, and increased density of Ins $\mathrm{P}_{3} \mathrm{Rs}$ (three times higher than in the rest of the cytoplasm). If diffusion is restricted, but without increased density of $\operatorname{Ins} \mathrm{P}_{3} \mathrm{Rs}$, no increase in $\mathrm{Ca}^{2+}$ is observed (not shown). Figure 4e has been obtained by numerical integration of three differential equations, simulating the evolution of the fraction of inhibited InsP $\mathrm{P}_{3}$ receptors $\left(R_{\mathrm{i}}\right)$, the concentration of cytosolic $\mathrm{Ca}^{2+}(C)$ and the concentration of $\operatorname{InsP}_{3}(I)$ :

$$
\begin{gathered}
\frac{\mathrm{d} R_{i}}{\mathrm{~d} t}=k_{+}\left(1-R_{i}\right) \frac{C^{n i}}{1+\left(\frac{C}{K_{\mathrm{A}}}\right)^{n a}}-k_{-} R_{i} \\
\frac{\partial C}{\partial t}=\alpha k_{1}\left(b+R_{a}\right)-V_{\mathrm{P}} \frac{C^{2}}{K_{\mathrm{P}}^{2}+C^{2}}+D_{\mathrm{C}} \nabla^{2} C \\
\frac{\partial I}{\partial t}=V_{\mathrm{b}}+J_{\mathrm{IP}}(\bar{r})-k_{\mathrm{d}} I+D_{\mathrm{I}} \nabla^{2} I
\end{gathered}
$$

where $R_{a}=\left(1-R_{i}\right) \frac{I}{K+I} \frac{C^{n a}}{K^{n a}+C^{n a}}$ represents the fraction of open receptors.

Equation (1) reflects the activation/inhibition of the InsP ${ }_{3} \mathrm{R}$ by cytosolic $\mathrm{Ca}^{2}+$ Equation (2) describes changes in cytosolic $\mathrm{Ca}^{2+}$ concentration due to $\mathrm{Ca}^{2+}$ release from the endoplasmic reticulum assumed to remain constant, uptake through the SERCA pumps and diffusion. Equations (1) and (2) are based on Dupont and Swillens $s^{32}$ and represent a classical description of $\mathrm{Ca}^{2+}$ dynamics ${ }^{47}$ Equation (3) is a simplified description of intracellular $\mathrm{InsP}_{3}$ dynamics, taking into account synthesis through PLC at a basal rate $\left(V_{\mathrm{b}}\right)$, localized stimulated synthesis due to bacterial invasion $\left(J_{\mathrm{IP}}\right)$, linear degradation $\left(k_{\mathrm{d}} I\right)$ and diffusion. These equations have been integrated with MatLab (ode23) in two dimensions, using a $60 \times 24$ mesh to simulate the dynamics occurring in a $25 \times 10-\mu \mathrm{m}$ cell The geometry of the system is schematized in Supplementary Fig. S12.

The parameters are defined in Supplementary Table S1. Initial conditions correspond to the steady-state situation in the absence of bacterial invasion (see Supplementary Methods for more detailed information).

\section{References}

1. Coburn, B., Sekirov, I. \& Finlay, B. B. Type III secretion systems and disease. Clin. Microbiol. Rev. 20, 535-549 (2007).

2. Phalipon, A. \& Sansonetti, P. J. Shigella's ways of manipulating the host intestinal innate and adaptive immune system: a tool box for survival? Immunol. Cell Biol. 85, 119-129 (2007).

3. Ogawa, M., Handa, Y., Ashida, H., Suzuki, M. \& Sasakawa, C. The versatility of Shigella effectors. Nat. Rev. Microbiol. 6, 11-16 (2008).

4. Cornelis, G. R. The type III secretion injectisome. Nat. Rev. Microbiol. 4, $811-825$ (2006)

5. Munter, S., Way, M. \& Frischknecht, F. Signaling during pathogen infection. Sci. STKE 2006, re5 (2006).

6. Mounier, J. et al. The IpaC carboxyterminal effector domain mediates Src-dependent actin polymerization during Shigella invasion of epithelial cells. PLoS Pathog 5, e1000271 (2009). 
7. Handa, Y. et al. Shigella IpgB1 promotes bacterial entry through the ELMO-Dock180 machinery. Nat. Cell Biol. 9, 121-128 (2007).

8. Demali, K. A., Jue, A. L. \& Burridge, K. IpaA targets betal integrins and rho to promote actin cytoskeleton rearrangements necessary for Shigella entry. J. Biol. Chem. 281, 39534-39541 (2006).

9. Izard, T., Tran Van Nhieu, G. \& Bois, P. R. Shigella applies molecular mimicry to subvert vinculin and invade host cells. J. Cell. Biol. 175, 465-475 (2006).

10. Tran Van Nhieu, G. et al. Connexin-dependent inter-cellular communication increases invasion and dissemination of Shigella in epithelial cells. Nat. Cell. Biol. 5, 720-726 (2003).

11. Guttman, J. A. et al. Gap junction hemichannels contribute to the generation of diarrhoea during infectious enteric disease. Gut 59, 218-226 (2010).

12. Brown, M. D., Bry, L., Li, Z. \& Sacks, D. B. Actin pedestal formation by enteropathogenic Escherichia coli is regulated by IQGAP1, calcium, and calmodulin. J. Biol. Chem. 283, 35212-35222 (2008).

13. Wiles, T. J., Dhakal, B. K., Eto, D. S. \& Mulvey, M. A. Inactivation of host Akt/ protein kinase B signaling by bacterial pore-forming toxins. Mol. Biol. Cell. 19, 1427-1438 (2008)

14. Hybiske, K. \& Stephens, R. S. Exit strategies of intracellular pathogens. Nat. Rev. Microbiol. 6, 99-110 (2008).

15. TranVan Nhieu, G., Clair, C., Grompone, G. \& Sansonetti, P. Calcium signalling during cell interactions with bacterial pathogens. Biol. Cell. 96, 93-101 (2004)

16. Roy, D. et al. A process for controlling intracellular bacterial infections induced by membrane injury. Science 304, 1515-1518 (2004).

17. Coombes, B. K. \& Finlay, B. B. Insertion of the bacterial type III translocon: not your average needle stick. Trends Microbiol. 13, 92-95 (2005).

18. Gewirtz, A. T. et al. Salmonella typhimurium induces epithelial IL-8 expression via $\mathrm{Ca}^{2+}$-mediated activation of the NF-kappaB pathway. J. Clin. Invest. 105, 79-92 (2000).

19. Berridge, M. J. Calcium microdomains: organization and function. Cell Calcium 40, 405-412 (2006).

20. Demuro, A. \& Parker, I. Imaging single-channel calcium microdomains. Cell Calcium 40, 413-422 (2006).

21. Bootman, M. D., Lipp, P. \& Berridge, M. J. The organisation and functions of local $\mathrm{Ca}^{2+}$ signals. J. Cell Sci. 114, 2213-2222 (2001).

22. Rizzuto, R. \& Pozzan, T. Microdomains of intracellular Ca2 +: molecular determinants and functional consequences. Physiol. Rev. 86, 369-408 (2006).

23. Wei, C. et al. Calcium flickers steer cell migration. Nature 457, 901-905 (2009).

24. Berridge, M. J. Inositol trisphosphate and calcium signalling mechanisms. Biochim. Biophys. Acta 1793, 933-940 (2009).

25. De Smedt, F., Verjans, B., Mailleux, P. \& Erneux, C. Cloning and expression of human brain type I inositol 1,4,5-trisphosphate 5-phosphatase. High levels of mRNA in cerebellar Purkinje cells. FEBS Lett. 347, 69-72 (1994).

26. Hattori, M. et al. Distinct roles of inositol 1,4,5-trisphosphate receptor types 1 and 3 in Ca2 + signaling. J. Biol. Chem. 279, 11967-11975 (2004).

27. Fukatsu, K., Bannai, H., Inoue, T. \& Mikoshiba, K. Lateral diffusion of inositol 1,4,5-trisphosphate receptor type 1 in Purkinje cells is regulated by calcium and actin filaments. J. Neurochem. 114, 1720-1733 (2010).

28. Flannagan, R. S., Harrison, R. E., Yip, C. M., Jaqaman, K. \& Grinstein, S. Dynamic macrophage 'probing' is required for the efficient capture of phagocytic targets. J. Cell Biol. 191, 1205-1218 (2010).

29. Arrio-Dupont, M., Foucault, G., Vacher, M., Devaux, P. F. \& Cribier, S. Translational diffusion of globular proteins in the cytoplasm of cultured muscle cells. Biophys. J. 78, 901-907 (2000).

30. Potma, E. O. et al. Reduced protein diffusion rate by cytoskeleton in vegetative and polarized dictyostelium cells. Biophys. J. 81, 2010-2019 (2001).

31. Varnai, P. \& Balla, T. Live cell imaging of phosphoinositides with expressed inositide binding protein domains. Methods 46, 167-176 (2008).

32. Dupont, G. \& Swillens, S. Quantal release, incremental detection, and longperiod $\mathrm{Ca} 2+$ oscillations in a model based on regulatory $\mathrm{Ca} 2+$-binding sites along the permeation pathway. Biophys. J. 71, 1714-1722 (1996).

33. Callamaras, N. et al. Activation and co-ordination of InsP3-mediated elementary $\mathrm{Ca} 2+$ events during global $\mathrm{Ca} 2+$ signals in Xenopus oocytes. J. Physiol. 509, 81-91 (1998).
34. Griffiths, E. J. \& Rutter, G. A. Mitochondrial calcium as a key regulator of mitochondrial ATP production in mammalian cells. Biochim. Biophys. Acto 1787, 1324-1333 (2009).

35. Contreras, L., Drago, I., Zampese, E. \& Pozzan, T. Mitochondria: the calcium connection. Biochim. Biophys. Acta 1797, 607-618 (2010).

36. Carneiro, L. A. M. et al. Shigella induces mitochondrial dysfunction and cell death un non-myeloid cells. Cell Host Microbe 5, 123-136 (2009).

37. Palmer, A. E. et al. Ca2 + indicators based on computationally redesigned calmodulin-peptide pairs. Chem. Biol. 13, 521-530 (2006).

38. Penefsky, H. S. Mechanism of inhibition of mitochondrial adenosine triphosphatase by dicyclohexylcarbodiimide and oligomycin: relationship to ATP synthesis. Proc. Natl Acad. Sci. USA 82, 1589-1593 (1985).

39. Ruetz, T. J., Lin, A. E. \& Guttman, J. A. Shigella flexneri utilizes the spectrin cytoskeleton during invasion and comet tail generation. BMC Microbiol. 12, 36 (2012).

40. Smith, I. F., Wiltgen, S. M., Shuai, J. \& Parker, I. Ca2 + puffs originate from pre-established stable clusters of inositol-trisphosphate receptors. Sci. Signal 2 ra77 (2009).

41. Rahman, T-U, Skupin, A., Falcke, M. \& Taylor, C. W. Clustering of IP3 receptors by IP3 retunes their regulation by IP 3 and $\mathrm{Ca}^{2+}$. Nature 458, 655-659 (2009).

42. Bergounioux, J. et al. Calpain activation by the Shigella flexneri effector VirA regulates key steps in the formation and life of the bacterium's epithelial niche. Cell Host Microbe 11, 240-252 (2012).

43. Hänisch, J., Kölm, R., Wozniczka, M., Bumann, D., Rottner, K. \& Stradal, T. E. Activation of a RhoA/myosin II-dependent but Arp2/3 complex-independent pathway facilitates Salmonella invasion. Cell Host Microbe 9, 273-285 (2011).

44. Kuiper, J. W. et al. Creatine kinase-mediated ATP supply fuels actin-based events in phagocytosis. PLoS Biol. 6, e51 (2008).

45. Menard, R. \& Sansonetti, P. J. Shigella flexneri: isolation of noninvasive mutants of gram-negative pathogens. Methods Enzymol. 236, 493-509 (1994).

46. Palmer, A. E. et al. $\mathrm{Ca} 2+$ indicators based on computationally redesigned calmodulin-peptide pairs. Chem. Biol. 13, 521-530 (2006).

47. Sneyd, J., Falcke, M., Dufour, J. F. \& Fox, C. A comparison of three models of the inositol trisphosphate receptor. Prog. Biophys. Mol. Biol. 85, 121-140 (2004)

\section{Acknowledgements}

We thank Jeremy Teillon from the CIRB imaging facility and Alain Joliot for technical help. We are grateful to Jean-Pierre Mauger for critical reading of the manuscript. This work was supported by fundings from the Inserm, the Collège de France, the Agence Nationale pour la Recherche grant ANR-12-BSV3-0017_01 and the National Institute of Health grant AI067949. L.C. is supported by an interface contract between Inserm and AP-HP (Le Kremlin-Bicetre Hospital). G.D. is Senior Research Associate at the Belgian FNRS.

\section{Author contributions}

G.T.V.N. and L.C. designed, performed, analysed experiments and wrote the manuscript B.K.L., J.Z, SP. and F.P. performed and analysed experiments. P.S., C.E., J.K.K. and P.G.S. analysed experiments. G.D. performed the simulations and analysis.

\section{Additional information}

Supplementary Information accompanies this paper at http://www.nature.com/ naturecommunications

Competing financial interests: The authors declare no conflicting financial interests.

Reprints and permission information is available at http://npg.nature.com/ reprintsandpermissions/

How to cite this article: Tran Van Nhieu, G. et al. Actin-based confinement of calcium responses during Shigella invasion. Nat. Commun. 4:1567 doi: 10.1038/ncomms2561 (2013). 